\title{
BEHAVIOURAL RESPONSES OF TWO POPULAR ORNAMENTAL CARPS, CYPRINUS CARPIO L. AND CARASSIUS AURATUS (L.), TO MONOCULTURE AND POLYCULTURE CONDITIONS IN AQUARIA
}

\author{
Prithwiraj JHA, Sushruta JHA, Bikash C. PAL, Sudip BARAT* \\ Department of Zoology, University of North Bengal, District Darjeeling, \\ West Bengal, India
}

\begin{abstract}
Jha P., Jha S., Pal B.C., Barat S. 2005. Behavioural responses of two popular ornamental carps, Cyprinus carpio L. and Carassius auratus (L.), to monoculture and polyculture conditions in aquaria. Acta Ichthyol. Piscat. 35 (2): 133-137.
\end{abstract}

\begin{abstract}
Experiments were conducted to document behavioural responses of koi carp, Cyprinus carpio L., and goldfish, Carassius auratus (L.) to monoculture and polyculture conditions in aquaria. Two parallel experiments, otherwise involving similar experimental protocols, were carried out with two batches of fish, fed with live tubifex worm (first batch) and live zooplankton (second batch). Each of the trials, randomized with respect to treatment, yielded data on aggressive encounters (chases, nips), both in presence and absence of food. The two species exhibited considerable variation in the extent and type of aggression displayed, koi carp being the more aggressive species. Frequency of attack increased in the presence of food. The impact of aggressive behaviour of koi carp was conspicuous by the increased level of attack on goldfish in polyculture trials in both experimental batches.
\end{abstract}

Key words: koi carp Cyprinus carpio, goldfish, Carassius auratus, aggressive behaviour, monoculture, polyculture conditions

\section{INTRODUCTION}

Fish polyculture is attempted by stocking two or more species with different feeding habits and different habitat preferences (Lutz 2003). The productivity of the aquatic system is thus increased by introducing more than one compatible fish species in a culture system, where the growth and survival of one species is not negatively affected by the other. To test the interactions between species in polyculture systems, behavioural studies on fish-fish interactions are suitable evaluation tools (Milstein 1992, Kramer et al. 1997, Shumway 1999).

Prominent among freshwater ornamental carps cultured in India are koi carp, Cyprinus carpio L., and goldfish, Carassius auratus (L.). Since the marketable size of koi carp and goldfish are quite similar (> $4.0 \mathrm{~g})$, and both species require a similar culture period of 11 to 12 weeks to attain the marketable size (Jha and Barat 2005 a), there is a general tendency among fish producers and hobbyists to stock them together. However, further work on the impacts of polyculture on the overall culture performance of each species is necessary. Behavioural studies on the interspecific interrelationships is one tool for evaluation. The objective of the present study was to compare the behavioural responses of koi carp and goldfish stocked in mono- and polyculture combinations to assess their behavioural compatibility.

\section{MATERIALS AND METHODS}

About 2- to 3-week-old larvae of bekko type koi carp, Cyprinus carpio L. $(0.13 \pm 0.03 \mathrm{~g} ; n=50)$, and goldfish, Carassius auratus (L.) $(0.18 \pm 0.05 \mathrm{~g} ; n=50)$ were collected from a local hatchery (Rainbow Ornamentals, Raninagar, Jalpaiguri, India) and transferred to a laboratory at the University of North Bengal, where they were acclimated for nearly three weeks prior to the study. At first, the koi carp and goldfish larvae were divided into two batches. Both batches were subjected to similar acclimation and experimental protocols, except for the food applied to each batch, which was different. The fish were maintained in aerated and filtered aquaria, under artificial lights (12 L : $12 \mathrm{D}$ photoperiod). The tanks were filled with tap water (water volume $150 \mathrm{~L} ; 20$ fish/tank). The fish were fed live tubifex worm (first batch) and live zooplankton (second batch) during this period, offered daily in the amount of $5 \%$ body weight of the fish stocked (the actual amount of food was adjusted every weekly). The same food was used later during the experiments. The tubifex food was procured from the local market, while zooplankton was cultured in con- 
crete tanks under protocols described earlier (Jha and Barat $2005 \mathrm{~b}$ ). The physico-chemical conditions were similar in all the holding tanks (temperature $24-26^{\circ} \mathrm{C} ; \mathrm{pH} 7.0-7.2$; dissolved oxygen content $6.5-6.8 \mathrm{mg} \cdot \mathrm{L}^{-1}$ ).

Two parallel experiments were conducted for the two batches during 15 consecutive days from 20 August to 3 September, 2004 in six 150-L tanks (three tanks for each experiment) maintained under physico-chemical conditions similar to those of the holding tanks (temperature 23-26 ${ }^{\circ} \mathrm{C}$; $\mathrm{pH}$ 6.9-7.2; dissolved oxygen 6.5-6.9 $\mathrm{mg} \cdot \mathrm{L}^{-1}$ ). In these trials, monoculture or polyculture groups totalling 20 fish were used in each aquarium. The treatments (for each batch) were: (1) koi carp, monoculture; (2) goldfish, monoculture; and (3) koi carp and goldfish, polyculture, stocked at 1:1. On the average, the 5- to 6-week-old fish used during the study had a mean weight of $0.86 \pm 0.11 \mathrm{~g}$ (koi carp; $n=50$ ) and $1.49 \pm 0.38 \mathrm{~g}$ (goldfish; $n=50$ ).

The order of trials was randomized with respect to treatment and 15 replicate trials (one trial every day) were performed for each treatment. Grid markings on the tanks allowed the location (depth) of the fish in the water column to be estimated. The tanks were screened with black art paper from four sides and an eye slit was cut on the front side, which allowed the experimenter to observe and record the behaviour of fish without disturbing them. In each trial, the fish were placed in the tank and left to settle for $1 \mathrm{~h}$. This was followed by a period of focal sampling (Martin and Bateson 1990) for 5 minutes in which the occurrence and direction of all antagonistic interactions (chases, nips) involving a randomly chosen individual of each species were recorded. Then, a small amount of food was applied and the above procedures were repeated. Each trial therefore yielded data on aggressive encounters of the species concerned, both before food application and in the presence of food.

Aggressive behaviour was measured as the number of attacks, defined as accelerated swimming movements or a sudden burst of speed by one fish towards another (chases), followed by nips - a bite, and/or flight or pursuit. In the first batch, live tubifex were applied in feeding baskets and placed on the floor of the tanks. For the second batch, the food (plankton) was added centrally onto the water surface and the live plankton dispersed rapidly over the entire water surface. This way of offering the food generally increases feeding opportunity and promotes uniformity of feeding and growth (McCarthy et al. 1999, Gomez-Laplaza 2002).

Differences in the mean chasing and mean nipping frequency recorded for each species between the monoculture and polyculture treatments were examined using Student's paired t-test (Student 1908, Gupta 2000). Significance was accepted at $P<0.05$. Separate analyses were carried out on the "food present" and "food absent" (before application of food) data for each batch. Primary data (number of nips and chases) were log-transformed prior to the analysis and standardised by dividing the number of attacks received by focal fish per trial by the number of potential aggressors. For interspecific attacks, the number of aggressors was $n$, where $n=$ group size of the attacking species. For conspecific attacks, the number of aggressors was $n-1$.

\section{RESULTS}

Attack levels as estimated from the standardised chasing and nipping frequency per trial for both species were significantly higher in polyculture treatments, compared to monoculture treatments, both before food application and in the presence of food $(P<0.05)$. The attack level also increased markedly in the presence of food, compared to when food was absent in both experimental batches (Table 1). These aggressive acts were very short, and often did not involve actual physical contact. When physical contact occurred, in most cases it involved a momentary pinch by pushing the snout of one fish against the abdomen or fins of another. Total attacks per trial (chases plus nips) as estimated from the different species level interactions (Table 1) showed that goldfish received more attacks under polyculture conditions in both batches, compared to koi carp. Under monoculture conditions, the incidence of attacks in goldfish tanks were lower compared to koi carp tanks, marking the koi carp as a more aggressive species. Chasing (Figs. 1 and 2) and nipping (Figs. 3 and 4) frequencies followed similar trends, although the chasing frequency was higher than the nipping frequency (Table 1).

\section{DISCUSSION}

The two species exhibited considerable variation in the extent and type of aggression displayed. Goldfish in monoculture treatments appeared less aggressive, compared to monocultured koi carp in both experimental batches. Even in the polyculture treatments, goldfish attacked conspecifics or other species (koi carp) very rarely. On the other hand, koi carp were overwhelmingly more aggressive. The frequency of attack increased significantly in the presence of food. Food was shown to increase the rates of aggression in gouramis, Trichogaster trichopterus (Pallas) (Syarifuddin and Kramer 1996) and poeciliids, Gambusia holbrooki (Girard) and Xiphophorus helleri Heckel (Warburton and Madden 2003). The broader diversity of species-specific behaviours and salient stimuli may also have enhanced the levels of activity. In a study of conspecific and interspecific interactions between brook trout, Salmo gairdneri (Oncorhynchus mykiss (Walbaum)), Newman (1956) postulated that the presence of food increased feeding activity, which in turn increased aggressive activity as the focus of attacks was displaced from the food to fellow fish of both species. He further noted that feeding fish displayed some movements that are associated with aggression, such as body undulations, swift darting and biting, and suggested that such movements constituted sign stimuli eliciting attacks from other species.

The significantly higher rate of attacks in the polyculture treatments compared to monoculture conditions for both batches of fish undermines the very logic behind stocking koi carp and goldfish together. Although the impact of nipping on the rate of spinal and caudal abnormalities or fin deformities were not estimated in the 
Table 1

Standardised frequency of attacks calculated for koi carp $(\mathrm{K})$ and goldfish $(\mathrm{G})$ in the two experimental batches

$\begin{array}{llll}\text { Interaction } & n & \text { Total attacks/trial } & \text { Nips : chases } \quad \text { Food : no food }\end{array}$

Monoculture

$\begin{array}{lrrrc}\mathrm{K} \rightarrow \mathrm{K} & 982 & 1.258 & 0.426 & 2.778 \\ \mathrm{G} \rightarrow \mathrm{G} & 496 & 0.544 & 0.424 & 3.945 \\ \text { Polyculture } & & & & \\ \mathrm{K} \rightarrow \mathrm{K} & 345 & 0.913 & 0.520 & 3.492 \\ \mathrm{~K} \rightarrow \mathrm{G} & 2753 & 2.944 & 0.584 & 1.769 \\ \mathrm{G} \rightarrow \mathrm{G} & 328 & 0.846 & 0.065 & 1.735 \\ \mathrm{G} \rightarrow \mathrm{K} & 161 & 0.077 & 0.185 & +\end{array}$

Second Batch (Zooplankton as food)

Monoculture

$\begin{array}{crrrr}\mathrm{K} \rightarrow \mathrm{K} & 660 & 0.845 & 0.335 & 1.807 \\ \mathrm{G} \rightarrow \mathrm{G} & 369 & 0.294 & 0.556 & 2.379 \\ \text { Polyculture } & & & & \\ \mathrm{K} \rightarrow \mathrm{K} & 233 & 0.571 & 0.903 & 1.584 \\ \mathrm{~K} \rightarrow \mathrm{G} & 2246 & 2.708 & 0.605 & 1.396 \\ \mathrm{G} \rightarrow \mathrm{G} & 537 & 1.330 & 0.360 & 1.509 \\ \mathrm{G} \rightarrow \mathrm{K} & 174 & 0.156 & 0.902 & +\end{array}$

"Total attacks" = chases plus nips; (+) indicates an increase in the presence of food, but where a ratio cannot be calculated due to a zero "no food" value

present experiment, it could be suggested that sustained attacks, particularly on goldfish by koi carp under polyculture conditions could induce stress and increase the rate of deformities in a pond polyculture. It should be remembered that ornamental fish need to be visually attractive to be acceptable on the market, and deformed or stressed fish could be aesthetically unattractive to potential customers (Jha and Barat 2005 b).
The two food items used the two experimental batches (tubifex and plankton) were selected with a due consideration to the food availability under pond conditions. The impact of aggressive behaviour of koi carp was clearly demonstrated by the increased level of attack on goldfish in the polyculture treatments in both the experimental batches. Working with introduced poeciliid, Gambusia holbrooki and native Australian fish, Pseudomugil signifer Kner, Howe et

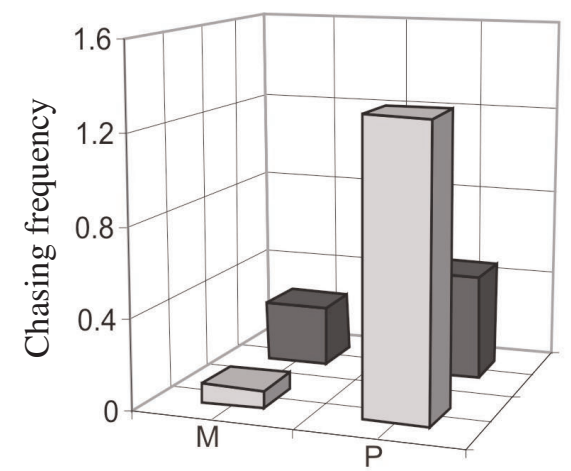

Food absent

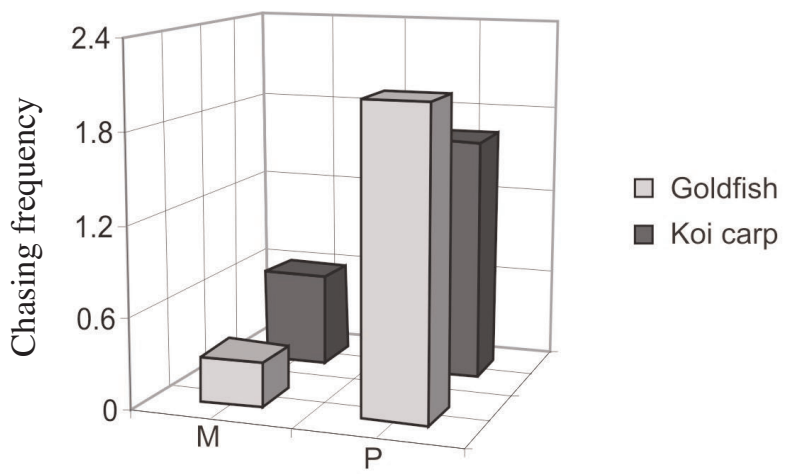

Food present

Fig. 1. Standardised (per capita) chasing frequency per trial estimated for koi carp and goldfish under monoculture (M) and polyculture (P) conditions in aquaria in the presence and absence of food (tubifex) 


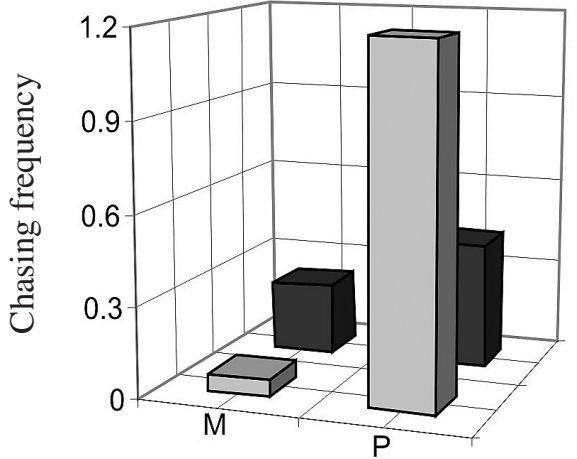

Food absent

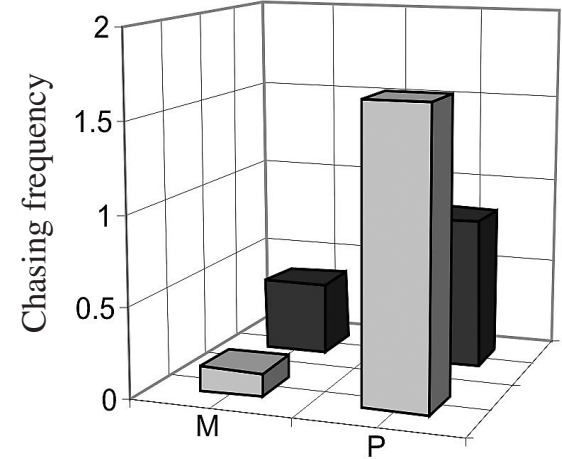

Food present
Goldfish

Koi carp

Fig. 2. Standardised (per capita) chasing frequency per trial estimated for koi carp and goldfish under monoculture (M) and polyculture $(\mathrm{P})$ conditions in aquaria in the presence and absence of food (plankton)

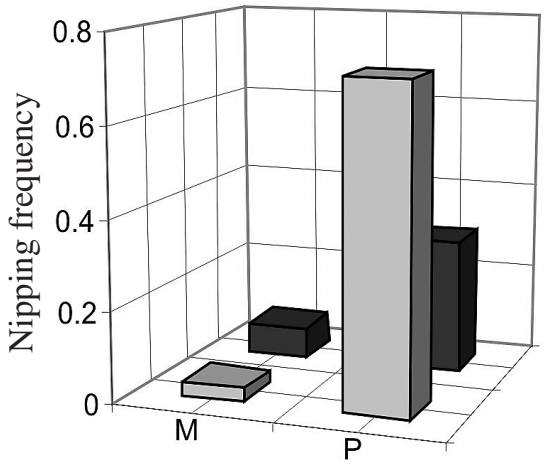

Food absent

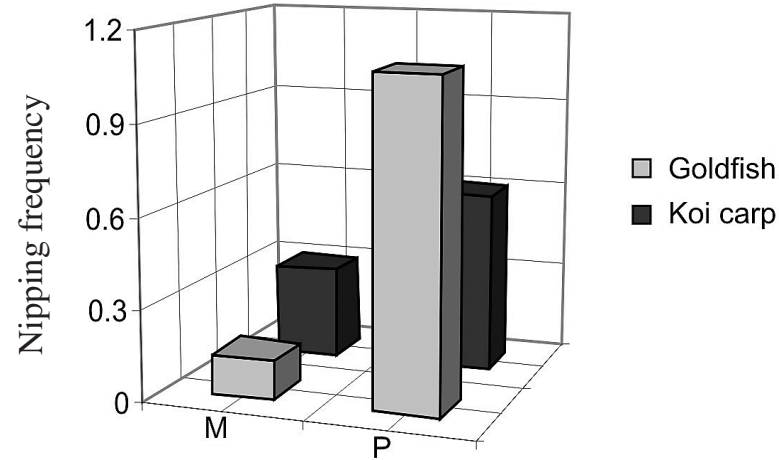

Food present

Fig. 3. Standardised (per capita) nipping frequency per trial estimated for koi carp and goldfish under monoculture (M) and polyculture $(\mathrm{P})$ conditions in aquaria in the presence and absence of food (tubifex)

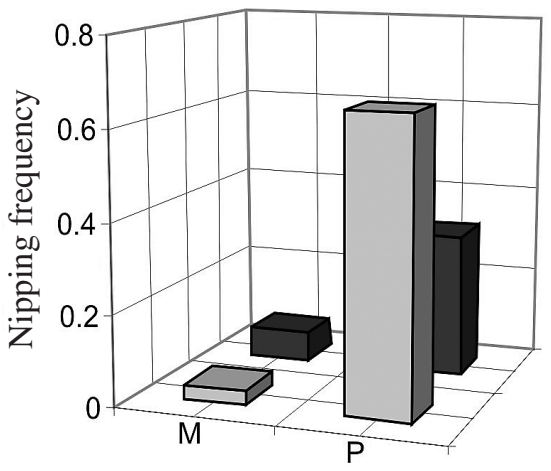

Food absent

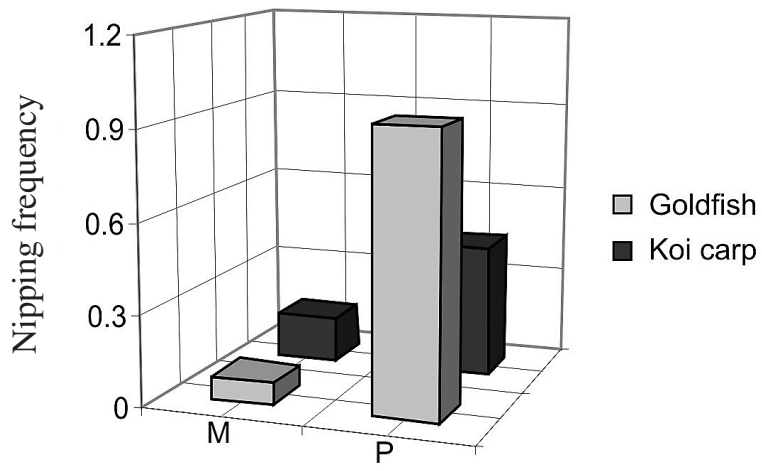

Food present

Fig. 4. Standardised (per capita) nipping frequency per trial estimated for koi carp and goldfish under monoculture (M) and polyculture $(\mathrm{P})$ conditions in aquaria in the presence and absence of food (plankton)

al. (1997) observed that the prerequisites for competition exist when mixed populations of fish species are trapped in shrinking ponds during drought. In India, ornamental fish ponds are generally much smaller, compared to other aquaculture ponds, and competition pressure may severely affect the production status of the "non aggressive" species under such confined habitat conditions.
Although the present laboratory-based findings are not sufficient to be applied in a predictive way to judge interspecific interrelationships in ponds, they do illustrate behavioural mechanisms by which koi carp may negatively impact goldfish under confined conditions in ponds. A major limitation of the present study lies in its direct observation method allowing space for individual errors 
and selective judgments. Nevertheless, the data are clearly indicative of behavioural interactions between the species concerned and further studies are encouraged to increase precision of observations (e.g. by video-recording and electronic image analysis systems). Further research is also required to investigate how dynamic behavioural interactions are affected by variation in abundance ratios as well as food availability and temperature, i.e. factors that play significant roles in tropical pond conditions.

\section{ACKNOWLEDGMENTS}

The authors wish to express their gratitude to Kripan Sarkar, owner of Rainbow Ornamental Fish Farm, Jalpaiguri, India, for supplying the experimental fish. The authors are grateful to Culum Brown, Institute of Cell, Animal and Population Biology, University of Edinburgh, United Kingdom, and Luis M. Gomez-Laplaza, Departamento de Psicologia, Universidad de Oviedo, Spain, for their cooperation and suggestions on the research plan, and to two anonymous reviewers for their critical comments which helped to improve the manuscript. Chitta R. Nayak, Computer Centre, University of North Bengal assisted in the statistical analysis.

\section{REFERENCES}

Gomez-Laplaza L.M. 2002. Social status and investigatory behaviour in the angelfish (Pterophyllum scalare). Behaviour 139: 1469-1490.

Gupta S.P. 2000. Statistical Methods. 28th edn. Sultan Chand and Sons, New Delhi.

Howe E., Howe C., Lim R., Burchett M. 1997. Impact of the introduced poeciliid Gambusia holbrooki (Girard, 1859) on the growth and reproduction of Pseudomugil signifer (Kner, 1865) in Australia. Marine and Freshwater Research 48: 425-434.

Jha P., Barat S. 2005 a. The effect of stocking density on growth, survival rate, and number of marketable fish produced of koi carps, Cyprinus carpio vr. koi, in concrete tanks. Journal of Applied Aquaculture 17: 89-102.
Jha P., Barat S. 2005 b. Management induced changes in food selection, growth and survival of koi carp, Cyprinus carpio var. koi L., in tropical ponds. The Israeli Journal of Aquaculture Bamidgeh 57: 115-124.

Kramer D.L., Rangeley R.W., Chapman L.J. 1997. Habitat selection: patterns of spatial distribution from behavioural decisions. pp. 37-80. In: Godin G.J. (ed.) Behavioural Ecology of Teleost Fishes. Oxford University Press, Oxford.

Lutz C.G. 2003. Polyculture: principles, practices, problems and promise. Aquaculture Magazine 29 (2): 34-39.

Martin P., Bateson P. 1990. Measuring Behaviour. Cambridge University Press, Cambridge.

McCarthy I.D., Gair D.J., Houlihan D.F. 1999. Feeding rank and dominance in Tilapia rendelii under defensible and indefensible patterns of food distribution. Journal of Fish Biology 55: 854-867.

Milstein A. 1992. Ecological aspects of fish interactions in polyculture ponds. Hydrobiologia 231: 177-186.

Newman M.A. 1956. Social behaviour and interspecific competition in two trout species. Physiological Ecology 29: 64-81.

Shumway C.A. 1999. A neglected science: applying behaviour to aquatic conservation. Environmental Biology of Fishes 55: 183-201.

Student 1908. Probable error of a correlation coefficient. Biometrika 6: 302-310.

Syarifuddin S., Kramer D.L. 1996. The effect of group size on space use and aggression at a concentrated food source in blue gouramis, Trichogaster trichopterus (Pisces: Belontiidae). Environmental Biology of Fishes 46: 289-296.

Warburton K., Madden C. 2003. Behavioural responses of two native Australian fish species (Melanotaenia duboulayi and Pseudomugil signifer) to introduced poeciliids (Gambusia holbrooki and Xiphophorus helleri) in controlled conditions. Proceedings of the Linnean Society of New South Wales 124: $115-123$.

Received: 29 August 2005 Accepted: 17 November 2005 